Target article author: Manvir Singh

Abstract word count: 59

Main text word count: 994

Reference word count: 462

Total word count: 1600

The Evolution of the Shaman's Cultural Toolkit

\author{
Aiyana K. Willard ${ }^{a}$ \\ aiyana.willard@anthro.ox.ac.uk \\ www.aiyanawillard.com \\ Yo Nakawake \\ yo.nakawake@anthro.ox.ac.uk \\ www.sites.google.com/site/ynakawake/home \\ Jonathan Jonga, $b$ \\ jonathan.jong@coventry.ac.uk \\ www.jonathanjong.ninja
}

anstitute of Cognitive \& Evolutionary Anthropology, Oxford University, 51-53 Banbury Road, Oxford UK, OX2 6PE

bCentre for Psychology, Behavior \& Achievement, Coventry University, Priory Street, Coventry, United Kingdom, CV1 5FB

All authors are grateful for financial support from the Templeton World Charity Foundation (TWCF0164). Correspondence concerning this article should be addressed to Aiyana K. Willard. 


\title{
The Evolution of the Shaman's Cultural Toolkit
}

\begin{abstract}
A complete picture of the cultural evolution of shamanism requires an understanding of how the professionalization of shamanism affects the distribution of knowledge within societies. We suggest that limiting knowledge to fewer people could impede the accumulation of functional knowledge within shamanism. Based on this, we make further predications about how the domain of shamanism could change and collapse.
\end{abstract}

The complexity of a cultural toolkit is highly dependent on the size and interconnectedness of the group that holds that toolkit (Derex, Beugin, Godelle, \& Raymond, 2013; Kline \& Boyd, 2010; Powell, Shennan, \& Thomas, 2009). If a society shrinks it can experience loss of cultural knowledge due to low fidelity transmission (Henrich, 2004). Even at its best, social learning is imperfect and details of tools, practices, and beliefs can be lost from one generation to the next. For example, if a society has a highly effective but complex fish hook design, it is unlikely that everyone in that society will master its construction. Given more minds the probability that at least one learner will learn everything necessary to recreate this technology increases; furthermore, given a larger number of people to learn from, the greater the probability that any specific learner will learn all the key pieces of knowledge (Muthukrishna, Shulman, Vasilescu, \& Henrich, 2013). Small variations in transmission can lead to innovation on a tool or piece of knowledge, rendering something like a fishhook more effective then the previous version (Aoki, Lehmann, \& Feldman, 2011; Eerkens \& Lipo, 2005). These innovations will be passed on to the next generation through the preferential learning from these experts (e.g. Chudek, Heller, Birch, \& Henrich, 2012; Henrich \& Gil-White, 2001). 
Singh discusses this in the context of a whole society losing shamanism, but not in the context of how these mechanisms affect the shaman's toolkit itself. Professionalization of shamanism reduces the number of teachers and learners capable of transmitting the shaman's knowledge. If only a few shamans and a few apprentices hold a specific type of knowledge, then we should expect lossy transmission. Even if we assume that the fidelity of transmission is extremely high at an individual level—each apprentice might train for years to perfectly learn the entire toolkit-the limited number of minds this knowledge iterates through will decrease the likelihood of new innovations accumulating. This type of high fidelity vertical transmission is conservative and is unlikely to produce much variation (Cavalli-Sforza \& Feldman, 1981). Even under conditions of perfect fidelity, the best we can hope for it that the shaman's toolkit remains static and simple. Under conditions of low fidelity, it will need to be largely reinvented in each generation.

In many of the domains that a shaman works this is unimportant. If the shaman's primary role is to control the weather, then a lack of fidelity and innovation will do no harm. There is no real causal connection between the details of the toolkit and its alleged effects. Therefore, the probability of this knowledge ever becoming functional is infinitesimal. For other domains, this possibility could pose real problems. Medicine and food acquisition can have tangible impacts on a society's ability to survive and prosper. Small innovations in these domains can accumulate over time to create effective tools that far surpass anything individuals could come 
up with on their own ( $c f$. Cavalli-Sforza \& Feldman, 1981; Henrich \& Henrich, 2010). Conversely, the failure to innovate could make a society less likely to thrive in their environment and less able to compete with other groups.

For shamanism to avoid becoming maladaptive these cases, other mechanisms need to be utilized to increase the probability of transmission and innovation. Competition between multiple shamans could increase the probability that functional practices arise, but if we follow Singh's claim, the selection pressures here are for more elaborate displays rather than functional skill sets. Even if this is not the case, the number of shamans is likely to remain too low for effective innovation in many societies. Domains like medicine can be maintained by dispersed parallel traditions outside of shamanism. As effective innovations accumulate in an area like medicine, the shaman's purview should become increasingly restricted to only the perceived spiritual aspects of the illness (Hultkrantz, 1985).

Paying attention to these dynamics allows us to make more specific predictions about how shamanism might change or disappear as societies become more complex. The role of a shaman in domains where functional knowledge is possible should become more restricted as these more effectual practices develop. In addition to the suggestions in Singh's paper, shamanism may disappear because the early professionalization of shamanism reduces the chances a shaman's toolkit can compete with the increasingly complex technology of a growing society. 
Further, given imperfect fidelity, the pieces of a shaman's toolkit that are maintained should become simpler and easier to transmit. Traits like redundancy though repetition of steps can increase the probability of this transmission (Acerbi \& Tennie, 2016). This type of routinization would make supernatural practices more ritualized over time ( $c f$. Humphrey \& Laidlaw, 1994). In some cases, shamanism's ecstatic trance states may thus be replaced with more easily transmitted ritualized action. If easy to transmit mechanisms like repetition and ritualization become part of what is passed on, they begin will to look increasingly like what we expect from religions (Whitehouse, 2004). Thus, another way shamanism may disappear is by changing into something looks increasingly like religion. This has been the case with of the religious traditions that followed many of prophets and religious founders Singh offers as examples of shamanism.

When we compare the roles of shamans with the roles of religious professionals as a broad category, the likelihood of this transition becomes more plausible. Priests and pundits are also privileged communicators with the supernatural world in domains of uncertainty (Weber, 1969), but these religious professionals are more likely to work in routinized ritual practices then the elaborate trance states of shamans ( $c f$. Whitehouse, 2004). Even in our increasingly technological world, the problem of uncertainty remains. Increases in safety and security have led to some decline in religious belief in some parts of the world (Norris \& Inglehart, 2004), yet religion worldwide has shown little decline (Stark, 1999; Stark \& Bainbridge, 1985). The 
problem of coping with uncertainty remains, and managing this uncertainty frequently stays in the hands of religious professionals. 


\section{References:}

Acerbi, A., \& Tennie, C. (2016). The role of redundant information in cultural transmission and cultural stabilization. Journal of Comparative Psychology, 130(1), 62-70. http://doi.org/10.1037/a0040094

Aoki, K., Lehmann, L., \& Feldman, M. W. (2011). Rates of cultural change and patterns of cultural accumulation in stochastic models of social transmission. Theoretical Population Biology, 79(4), 192-202. http://doi.org/10.1016/j.tpb.2011.02.001

Cavalli-Sforza, L. L., \& Feldman, M. W. (1981). Cultural transmission and evolution: a quantitative approach. Princeton, NJ: Princeton University Press.

Chudek, M., Heller, S., Birch, S., \& Henrich, J. (2012). Prestige-biased cultural learning: bystander's differential attention to potential models influences children's learning. Evolution and Human Behavior, 33(1), 46-56. http://doi.org/10.1016/j.evolhumbehav.2011.05.005

Derex, M., Beugin, M.-P., Godelle, B., \& Raymond, M. (2013). Experimental evidence for the influence of group size on cultural complexity. Nature, 503(7476), 389391. http://doi.org/10.1038/nature12774

Eerkens, J. W., \& Lipo, C. P. (2005). Cultural transmission, copying errors, and the generation of variation in material culture and the archaeological record. Journal of Anthropological Archaeology, 24(4), 316-334.

http://doi.org/10.1016/j.jaa.2005.08.001

Henrich, J. (2004). Demography and Cultural Evolution: How Adaptive Cultural Processes Can Produce Maladaptive Losses-The Tasmanian Case. American 
Antiquity, 69(2), 197-214.

Henrich, J., \& Gil-White, F. J. (2001). The evolution of prestige: freely conferred deference as a mechanism for enhancing the benefits of cultural transmission. Evolution and Human Behavior, 22(3), 165-196.

Henrich, J., \& Henrich, N. (2010). The evolution of cultural adaptations: Fijian food taboos protect against dangerous marine toxins. Proceedings of the Royal Society B: Biological Sciences, 277(1701), 3715-3724. http://doi.org/10.1098/rspb.2010.1191

Hultkrantz, Å. (1985). The shaman and the medicine-man. Social Science and Medicine. http://doi.org/10.2307/534522?ref=searchgateway:45e5c1245e0e61c9f1fe29fffad74e19

Humphrey, C., \& Laidlaw, J. (1994). The archetypal actions of ritual. Oxford, UK: Oxford University Press.

Kline, M. A., \& Boyd, R. (2010). Population size predicts technological complexity in Oceania. Proceedings of the Royal Society B: Biological Sciences, 277(1693), 2559-2564. http://doi.org/10.1098/rspb.2010.0452

Muthukrishna, M., \& Henrich, J. (2016). Innovation in the collective brain. Philosophical Transactions of the Royal Society B: Biological Sciences, 371(1690), 20150192-14. http://doi.org/10.1098/rstb.2015.0192

Muthukrishna, M., Shulman, B. W., Vasilescu, V., \& Henrich, J. (2013). Sociality influences cultural complexity. Proceedings of the Royal Society B: Biological Sciences, 281(1774), 20132511-20132511.

http://doi.org/10.1098/rspb.2013.2511 
Norris, P., \& Inglehart, R. (2004). Sacred and Secular: Religion and Politics Worldwide. Cambridge: Cambridge University Press.

Powell, A., Shennan, S., \& Thomas, M. G. (2009). Late Pleistocene Demography and the Appearance of Modern Human Behavior. Science, 324(5932), 1298-1301. http://doi.org/10.1126/science.1170165

Stark, R. (1999). Secularization, rip. Sociology of Religion, 60(3), 249-273.

Stark, R., \& Bainbridge, W. S. (1985). The Future of Religion: secularization, revival and cult formation. Berkeley: University of California Press.

Weber, M. (1969). The Sociology of Religion: Translated by Ephraim Fischoff, Introduction by Talcott Parsons. Beacon Press.

Whitehouse, H. (2004). Modes of religiosity: a cognitive theory of religious transmission. Walnut Creek, CA: AltaMira Press. 